\title{
Problems and Countermeasures of Chinese Ancient History Teaching in Colleges and Universities
}

\author{
Yang Min ${ }^{1}$ \\ ${ }^{1}$ Weinan Normal University, Weinan, Shaanxi, 714099
}

Keywords: colleges and universities; Chinese Ancient History; history major; classroom teaching; problem analysis

\begin{abstract}
In the history of colleges and universities, the importance of "Chinese Ancient History" curriculum system is very prominent, which runs through the entire process of Chinese historical development, from the primitive society, down to the late Qing Dynasty; curriculum content is more related to society, economy, politics, culture, science and technology, military affairs and education. Therefore, the teaching of "Ancient Chinese History" in colleges and universities has important practical significance. However, there are still many practical problems in the teaching of "Chinese Ancient History" at present, such as less teaching hours, outdated evaluation methods, simple teaching methods, and so on. This paper mainly analyzes the existing problems in the teaching of "Chinese Ancient History" in colleges and universities, and puts forward specific solutions.
\end{abstract}

\section{The Necessity of Carrying out the "Chinese Ancient History" Curriculum in Colleges and Universities}

Carrying out the course of "Ancient Chinese History" in colleges and universities can not only set up students' patriotism, promote the development of history, but also improve the overall quality of college students and enrich their professional knowledge. Therefore, it is of great significance. First of all, the course "Ancient Chinese History" can enhance students' sense of national pride and establish a sense of patriotism [1]. "Ancient Chinese History" is an objective factual record of the formation and development of the Chinese nation. "Ancient Chinese History" is to some extent an inheritance and expansion of the traditional Chinese culture and shoulders the important responsibility of cultivating students' patriotism and national spirit. Second, to promote the development of history. "Ancient Chinese History" is the basic compulsory course of history major in colleges and universities. It is also a source course and a key course for history majors. Therefore, its teaching quality and teaching effect will exert far-reaching influence on students' subsequent professional courses. Therefore, in this sense Speaking, "Ancient Chinese History" course will promote the development of history. Finally, to promote the all-round development of college students. In the 21st century, the demand for compound talents is getting higher and higher. Undergraduates must enhance understanding and reception of basic knowledge in multidisciplinary and multidisciplinary fields in order to further improve the overall quality of undergraduates. "Ancient Chinese History" is a basic history course, which helps students to understand the historical development of China. Therefore, carrying out the course of "Ancient Chinese History" can promote the all-round development of undergraduates [2].

\section{The Problems of "Chinese Ancient History" Teaching}

Although the teaching of the course of ancient Chinese history in colleges and universities is of great significance to improving the overall quality of college students, developing their patriotic awareness and promoting the development of history subjects, in the actual teaching process, there are still some aspects in the teaching of ancient Chinese history problem:

First of all, teaching methods are outdated. Since the beginning of Chinese civilization, the curriculum of "Ancient Chinese History" has been spanning for a long time. Since the time span of "Ancient Chinese History" has also lasted for more than 5,000 years, it has undergone three social 
forms of primitive society, slave society and feudal society. Its teaching Covering a wide range of content. However, the traditional teaching of "Ancient Chinese History" ignores the teaching principle of "General History of Guigong and Historiography of Knowledge". The teaching methods are too much emphasis on knowledge teaching, teachers occupy the leading position of classroom teaching, students are in a passive position, and teaching methods use one The traditional way of just a chalkboard. This teaching status does not highlight the students' subjective status and initiative, is not conducive to the cultivation of innovative talents. [3]

Second, there is less conflict between the content of the course and the teaching hours. Under normal circumstances, "Ancient Chinese History" as the history of professional basic courses to open more semesters, the total class time in about 140 hours, however, "Ancient Chinese History" curriculum span of great span, involving a wide range of knowledge, students not only need to master Basic knowledge, but also to highlight the key, more than one hundred hours obviously can not meet the teaching requirements, and if all the teaching methods, it is not conducive to the student's dominant position to play, for the cultivation of student innovation is also extremely unfavorable[4].

Finally, the assessment method is outdated and unitary. A fair, objective and scientific evaluation system is an important way to understand the situation of students' learning and development. [4] However, the single and obsolete teaching evaluation system of "Chinese ancient history" has always been outstanding. At this stage many colleges and universities on the evaluation of "Ancient Chinese History" course is divided into two parts, part of the peacetime performance, part of the final exam results, of which $20 \%$ of the usual performance, including attendance, homework class performance; the remaining $80 \%$ for the end.[5]Achievements, the use of closed-book, test questions, including terminology, questions and answers, material analysis, etc., the main test of students' knowledge and memory and text presentation capabilities. This type of examination has the drawbacks of being knowledge, light ability, heavy memory and light innovation, and can not guarantee the validity of the assessment. In particular, some students may pass the examination even if their final exams are not very satisfactory. Student learning initiative.

\section{Strategies to Improve the Teaching Effectiveness of "Chinese Ancient History"}

In view of the problems in the teaching of "Ancient Chinese History", it is suggested to improve it from the following aspects in order to improve the effectiveness of the teaching of "Ancient Chinese History":

\subsection{Adhere to two basic concepts of history}

History teaching should adhere to some basic theories and views of history [6]. The teaching of "Ancient Chinese History" should insist on the multiple historical perspective of global history and pluralistic integration. The world situation has undergone tremendous changes since the Second World War, the viewpoint of "European Center" has been shaken, and the British historian Balaclave put forward the view of "treating all ethnic groups fairly in all dynasties and in various regions of the world.". The theory emphasizes that in the world there is no absolutely independent geographical area, nor an absolute center. This kind of global history concept also brings new opportunities for the teaching of "Ancient Chinese History". Under the guidance of the global historical concept, "the ancient Chinese history "Teaching can avoid the single China and overemphasize the issue of China's independent region so as to raise the authenticity and objectivity of historical interpretation. [7] For example, the great historical significance of the formation of the Silk Road, the important status of China in the stage of world history during the Tang Dynasty, the expedition of Mongolia and the westward move of the Huns, etc., are just better ways to put ancient Chinese history in a global perspective Explore the context and laws of the development of ancient Chinese history and better enhance and refine the traditional cultural factors in "Ancient Chinese History." On the other hand, while upholding the concept of global history, we must uphold the concept of multi-dimensional Chinese history of the nation. The Chinese nation is not a single national concept. Studying ancient Chinese history based on the multi-integrated historical view of 
history has neither neglected the ethnic relations between the ethnic minorities and the Han nationality nor has they overemphasized the history of ethnic minorities, the process of integrating the Chinese nation is progressively accomplished. From this we can see that upholding the concept of global history can place Chinese history in a global perspective, while insisting on the concept of multi-dimensional national history emphasizes the uniqueness of Chinese history. Only by grasping these two principles of history can we provide reliable support.

\subsection{Balance the less teaching time and more teaching content with the extension of classroom}

There is less teaching hours and more contradictions in the teaching of Ancient Chinese History. How to complete the teaching tasks better without increasing the teaching hours is an important issue. The use of spare time to carry out "homework teaching" can effectively balance this contradiction. Teachers focus on guidance in the classroom teaching, ask questions, or summarize the clues, general laws of historical development, to enlighten students thinking, macroscopical grasp of history; and under the class requires students to summarize and summarize the main points of knowledge, this form of knowledge is not limits and emphasis are different, both can emphasize knowledge, but also can focus on ability, either written or oral, can be analyzed can also be summarized in order to allow students to reserve more room for independent study. Note that in the title, the teacher should avoid the operation of the topic there is too small or too broad, too partial or too deep, the problem is too broad, students need access to information too much, it will lose their interest in learning, the subject is too partial or too deep, students find information difficult, will deal with things, can not achieve the true purpose of teaching, so the teacher should be based on the actual situation of the library information and the actual ability of students to design difficult and moderate homework topics. For example, at the "Introduction" of "Ancient Chinese History", students can go to the library to collect various versions of "Ancient Chinese History" teaching materials and list the books. [8] This "homework" can not only guide students to learn How to use the library to retrieve knowledge, but also saves the class time for students to bibliography; and students in this process can also take the initiative to acquire knowledge, its ability to summarize, written and verbal ability, self-learning ability, analysis of the problem. The ability to wait a moment can be significantly improved. Of course, this kind of homework teaching needs supporting execution of other measures. The teacher should strengthen the restriction and supervision of the students, check the learning results in time, and include the completion of the students' work into the assessment mechanism. In addition to homework teaching, teachers can also use the study-based teaching method, which guides students to "read thousands of books and travel thousands of miles" to guide students out of school and exposure to the rich historical and cultural resources of the Chinese nation. , Vivid historical information to stimulate their interest in learning; and through field trips to students can also profoundly understand the long history of the Chinese nation's history and culture, through the study of glorious historical data and cultivate their noble moral sentiments and patriotic spirit, thereby enhancing Its humanistic quality and comprehensive quality[8].

\subsection{Reform evaluation system of "Chinese Ancient History" teaching}

Effective teaching evaluation can understand the learning effect of students and feedback learning opinions. Teachers can adjust teaching strategies at any time according to the evaluation results so as to improve the pertinence of classroom teaching. Thus, teaching assessment should serve professional learning contents. In view of the learning characteristics of "ancient Chinese history" and students' learning habits and teaching practice, it is necessary to reform and perfect the teaching evaluation system of "Ancient Chinese History". Many colleges and universities at this stage more than closed-book examination methods, to address this problem to be adjusted, do not simply emphasize closed-book exams for each semester, but to emphasize the students grasp the level of assessment of the course to understand and evaluate the learning outcomes of students and learning attitude. Increase daily occupation of the total score of the proportion of design work should be based on five dimensions to evaluate the completion of the situation, in which the title, form, write the standard of 15 points, the level of completion of the job is clear, the structure is reasonable, the focus is outstanding Accounting for 15 points, the view is correct, clear, the 
argument is sufficient, the argument is fully accounted for 30 points, guide the number of reference materials, the number accounted for 15 points, the theoretical analysis of practical problems can be applied and summarized, thinking 25 points. This evaluation system not only takes into account the mastery of students' basic knowledge, but also continuously explores the students' thinking ability and learning ability so as to enhance students' comprehensive mastery of the course. Moreover, the systematic and standardized professional examination system greatly enhances the "China The operability and measurability of ancient history teaching [9].

\section{Conclusion}

The course of ancient Chinese history is a basic course of history major with complicated teaching contents, strict teaching standards and high requirements on teaching conditions. With the constant development and improvement of the course knowledge system, the content of research and the research methods are continuously enriched. In the actual teaching, teachers should constantly improve their own knowledge system and constantly enrich the research content and research methods to make up for the shortcomings in teaching. The teaching of Ancient Chinese History should improve the limitations of traditional teaching methods, guide students to acquire more knowledge in a limited class, and internalize them into students' abilities. Apply a variety of teaching methods, improve, use a comprehensive approach, not only to ensure that students can master the system of professional knowledge, but also to cultivate my ability and skills, to maximize the learning potential of students to promote their development toward personalized. Of course, teachers still have to play their own guiding role, guide students to give full play to their own initiative, to stimulate their interest in learning, thereby enhancing its overall quality and professional ability.

\section{References}

[1] Chen Ming. Reflections on the Reform of Teaching Methods in Colleges and Universities [J]. Journal of Anhui University of Technology (Social Science Edition), 2013 (3): 101-102

[2] Chen Jun. A Comparative Study of Teaching Methodology between History Teaching in Normal Universities and New Curriculum Reform in Middle Schools [J]. West China Science and Technology, 2017 (11): 62-63

[3] Li Hongtu. Return to history - On the historical characteristics and ability training [J]. History Teaching, 2017 (1): 97-99

[4] Zhou Chunying. On China's financial history of teaching reform in several thinking [J]. History Teaching (University Edition), 2003 (7) .82-86

[5] Guo Xuexin. Humanities education and history teaching reform in colleges and universities [J]. History Teaching, 2017 (6).

[6] Xue Zhengchao. On the reform of the examination of college history major basic courses - A case study of ancient Chinese history [J], Adult Education in China, 2008 (5): 136-137

[7] Wu Chao. Some Suggestions on Strengthening the History Teaching Materials in Colleges and Universities [J], History Teaching, 2003 (5): 41-43

[8] Song Huqun, Gong Lizhu. Curriculum system of ancient Chinese history and textbook reform design [J], Journal of Henan University, 2015 (1): 110-118

[9] Fang Tie. Prospects for the Study of Ancient Chinese History in the 21st Century [J], Thought Front, 2012 (6): 100-103 